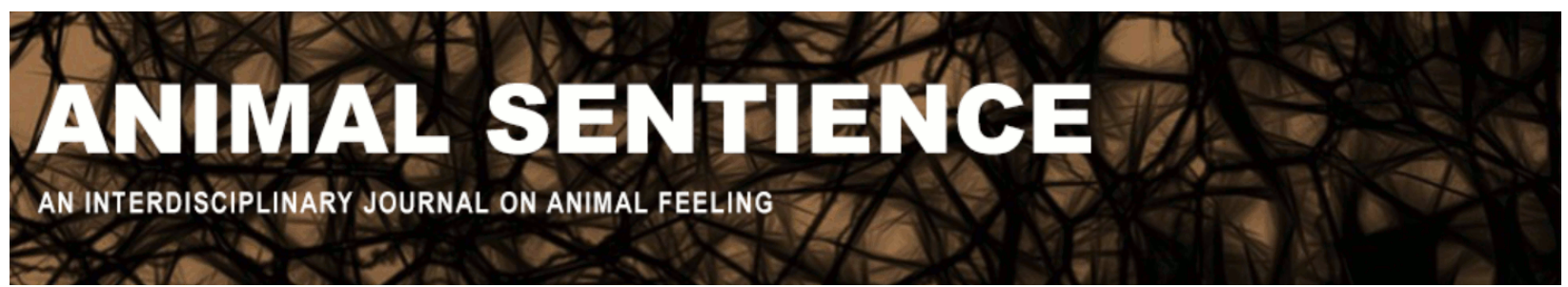

Stevens, E. Don (2016) Why is fish "feeling" pain controversial?. Animal Sentience $3(29)$

DOI: $10.51291 / 2377-7478.1055$

Date of submission: $2015-10-30$

Date of acceptance: 2015-12-13

(c)

This article has appeared in the journal Animal

Sentience, a peer-reviewed journal on animal

cognition and feeling. It has been made open access,

free for all, by WellBeing International and deposited

in the WBI Studies Repository. For more information,

please contact

wbisr-info@wellbeingintl.org.

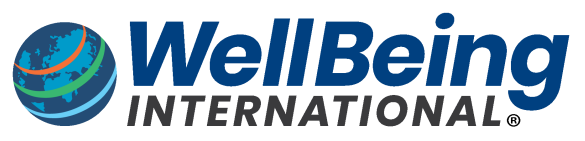

SOLUTIONS FOR PEOPLE, ANIMALS AND ENVIRONMENT 


\title{
Why is fish "feeling" pain controversial?
}

Commentary on Key on Fish Pain

\author{
E. Don Stevens \\ Biomedical Sciences \\ Atlantic Veterinary College
}

\begin{abstract}
In his excellent target article, Key (2016) develops a mechanistic argument in an attempt to show why it is unlikely that fish can "feel" pain or for that matter, "feel" anything. The topic is controversial and likely to achieve the goal of getting many hits for the inaugural issue of the new journal, Animal Sentience. In my view, the question is unlikely to be answered, for two reasons. First, because the proponents of the "fish feel pain" controversy are untrained and unskilled in the details and jargon of neurophysiology and/or neuroanatomy, and the opponents of the controversy, like Key, are untrained and unskilled in the details and jargon regarding the philosophy of consciousness. Second, the neural substrate of consciousness in any animal, including humans, has not been clearly delineated with absolute certainty.
\end{abstract}

E. Don Stevens dstevens@upei.ca, Adjunct Professor, UPEI, and Professor Emeritus of Integrative Biology, University of Guelph, is a fish physiologist who has spent the last decade studying the pragmatic and practical aspects of the "fish pain" question through the pharmacology and side-effects of analgesics in fishes. http://www.uoguelph.ca/ dstevens/

"We may feel sorry for the trout, the question is, 'does the trout feel sorry for itself?""

[paraphrased from Derbyshire 2003]

Key (2016) has made a valiant effort to present the argument against fish "feeling" pain based on his experience as a neurophysiologist. His argument is logical and is based on evidence from the scientific literature on neurophysiology and neuroanatomy. His arguments will be understood and appreciated by those with similar training and experience in neurophysiology and/or neuroanatomy. The controversy regarding fish "feeling" pain arises in part because those arguing that fish can "feel" pain lack this scientific training in neurophysiology and neuroanatomy; these are usually philosophers with no scientific training (but extremely good at arguing a case and usually familiar with the philosophical literature on consciousness), or animal behaviorists or behavioral ecologists with very little training or practical experimental experience in the areas of neurophysiology and neuroanatomy. In the past decade, the argument has morphed from whether fish can "feel" pain to an argument that concerns the extent to which fish are conscious or aware that they are aware. The problem concerns the word "feel" and how it is used. 
In the past decade, adjectives used to describe the way in which fish and other lower vertebrates behave or respond to stimuli in the environment has changed. Fish are described as anxious or fearful or happy or sad or having a particular type of personality. Some of this literature is promoted by persons trying to convince granting agencies that zebrafish are good models to test anxiolytics or antidepressants. Words that we use to describe human behaviors and responses have been adopted to describe behaviors in fish. This has not been helpful in gaining an understanding of the comparative aspects of consciousness. Key's arguments show that fish cannot "feel" pain and, by implication, have any other "feelings"; that is, fish cannot "feel" afraid or "feel" anxious. In my view, much of the problem arises from the difficulty in understanding exactly what is meant by "feel" or "feelings": How do they differ from emotion, mood, temperament, personality, disposition, motivation and/or cognition? To me, declaring that a fish is "feeling" hungry or "feeling" thirsty confuses the issue because a more appropriate term is motivated.

There is no question that individuals of any group of conspecific fish will respond to the same environmental stimulus in different ways behaviorally, just as they do physiologically - and the responses will vary with time in a particular fish. Do these differences between fish represent differences in "personality," and do the differences in time represent differences in "mood"? In my view, they do not, just as representing the response of a fish to a noxious stimulus is not necessarily a "feeling." Moreover, we know from thousands of studies that fish can learn a variety of tasks. However, the question remains whether this learning is associated with "feelings." We know that fish can "be in pain" in the sense that nociceptors can be activated. Key argues (and I agree) that it does not follow that a fish "being in pain" is the same as a fish "knowing it is in pain."

Essentially all of the complex behaviors that fish exhibit (including facial recognition) are shown also by social insects. Bees go many kilometers to find food, know their way back to the hive, and tell their friends the location of the good patch of food. Thus an argument that fish are conscious because they show complex behaviours must also apply to social insects and clearly, the neural substrates differ considerably. I agree with Key that "feelings" have a neural substrate and so it is unlikely that tomatoes have "feelings." The problem I have is that we do not know definitively the neural substrates of emotion, mood, temperament, personality, motivation, cognition, or feelings, and much of the confusion comes from lumping these terms together as though they are the same and will have the same neural substrate, identical in all animals.

Despite Key's valiant efforts, the question has not been answered to everyone's satisfaction and remains open. Importantly, the question has consequences because essentially all jurisdictions base legislation concerning welfare on the answer. I agree with Dawkins (2012) that much of this discussion has been a diversion and instead we should focus on fish welfare rather than on whether they are happy or have "feelings." 


\section{References}

Dawkins, M.S. (2012). Why Animals Matter. Oxford: Oxford University Press.

Derbyshire, S. (2003). Fishing for theories. http://www.spikedonline.com/newsite/article/5633\#.VjOBMYTVuQx

Key, B. (2016). Why fish do not feel pain. Animal Sentience 2016.003. 